Check for updates

Cite this: RSC Adv., 2019, 9, 39965

Received 19th September 2019 Accepted 26th November 2019

DOI: 10.1039/c9ra07556a

rsc.li/rsc-advances

\section{A high-nuclearity complex containing a decanuclear iron(III)/oxo cage in a football-like structure and rare $(R-/ S)$-hemiacetalate ligands in a butterfly-like format $\uparrow$}

\author{
Chunying Zheng, ${ }^{a}$ Mingyue Liang, ${ }^{a}$ Haofen Sun, ${ }^{a}$ Jiping $\mathrm{Ma},{ }^{a}$ Xuejun $\mathrm{Bi},{ }^{a}$ Yang Zhao, ${ }^{a}$ \\ Weiqiang $\operatorname{Tan}^{\star a}$ and Hui $\mathrm{Li}^{\star b}$ \\ A challenge in the field of high nuclearity Fe(III)/oxo cluster chemistry remains the development of new \\ synthetic methods to such molecules. In this work, the employment of pyridine-2-carboxaldehyde (py- \\ 2-al) in high-nuclearity transition-metal cluster chemistry has provided access to an unprecedented \\ decanuclear iron(III) complex, $\left[\mathrm{Fe}_{10}\left(\mathrm{NO}_{3}\right)_{7}(\mathrm{O})_{6}\left(\mathrm{OH}_{0.5}\right)_{2}((\mathrm{~S}) \text {-py-hemi })_{4}((R) \text {-py-hemi })_{4}\right] \cdot 4 \mathrm{H}_{2} \mathrm{O}(1)((R-/ S)$-py- \\ hemi $=(R-/ S)$-pyridine-2-carboxaldehyde hemiacetalate). The synthesis, beautiful structure and the \\ physical characterization (thermal gravimetric analysis, X-ray powder diffraction, proton nuclear \\ magnetic resonance, magnetic susceptibility) of complex 1 are described in this contribution. Complex 1 \\ provides a new route to obtain high nuclearity magnetic clusters with beautiful structures.
}

\section{Introduction}

High nuclearity clusters are of great interest currently, by virtue of their structural beauty and their important role in connecting micro to macro and quantum to classic regimes. ${ }^{1-6}$ There are numerous reasons for the interest in the synthesis and study of high nuclearity $3 \mathrm{~d}$ molecular metal clusters at moderate-to-high oxidation states. ${ }^{7,8}$ High nuclearity $3 \mathrm{~d}$ metal clusters, ${ }^{9,10}$ especially the ones that include $\mathrm{Ni}^{\mathrm{II}}, \mathrm{Co}^{\mathrm{II}}, \mathrm{Mn}^{\mathrm{III}}$ and $\mathrm{Fe}^{\mathrm{III}}$, often display fascinating structures, occasionally attractive properties, ${ }^{11-14}$ including single molecular magnet (SMM) and coupled SMM behavior, ${ }^{15-17}$ and promising applications for data storage, quantum computing and spintronics. ${ }^{18,19}$ The high nuclearity iron(III)-oxo chemistry has being developed over many years by virtue of their important role in bioinorganic chemistry, molecular magnetism and so on..$^{20-22}$ The high charge and Lewis acidity of $\mathrm{Fe}^{\mathrm{III}}$ strongly favor formation of oxide bridges from water molecules and thus foster formation of higher-nuclearity clusters. ${ }^{23-25}$ Although, there are many reports about high nuclearity iron(III)-oxo clusters with beautiful structures, such as high nuclearity iron(III)-oxo cages and wheels, and useful

\footnotetext{
${ }^{a}$ School of Environmental and Municipal Engineering, Qingdao University of Technology, Qingdao, 266580, People's Republic of China. E-mail: tanweiqiang@ qut.edu.cn; 3120110530@bit.edu.cn

${ }^{b}$ School of Chemistry and Chemical Engineering, Beijing Institute of Technology, Beijing 100081, People's Republic of China. E-mail: lihui@bit.edu.cn

$\dagger$ Electronic supplementary information (ESI) available: ${ }^{1} \mathrm{H}$ NMR spectra, IR spectrum, selected bond distances and angles of complex 1. CCDC 1919447. For ESI and crystallographic data in CIF or other electronic format see DOI: 10.1039/c9ra07556a
}

magnetic properties, a challenge in the field of high nuclearity $\mathrm{Fe}(\mathrm{III}) / \mathrm{oxo}$ cluster chemistry remains the development of new synthetic methods to such molecules through the employment of new chelating or bridging organic ligands. ${ }^{20-26}$ This investigation reports a 10-nuclear iron(III)/oxo cage with unusual $(R-/ S)$ hemiacetalate ligands $((R-/ S)$-py-hemi) by the employment of pyridine-2-carboxaldehyde (py-2-al), which displays football-like iron(III)/oxo cage, butterfly-like structure and antiferromagnetism. The synthesis, proposed mechanism and the physical characterization are described in this contribution.

\section{Experimental}

\subsection{Materials and physical measurements}

All starting materials and solvents used in this work were of analytical grade and purchased from Alfa Aesar Chemical Company without further purification. Elemental analyse (C, H, N) was performed on a Flash EA3000 microanalyzer. FTIR spectrum was recorded on a Nicolet-360 FTIR spectrometer. Thermo-gravimetric analyses (TGA) was carried out on a SEIKO TG/DTA 6200 thermal analyzer from $25{ }^{\circ} \mathrm{C}$ to $800{ }^{\circ} \mathrm{C}$ at a ramp rate of $10{ }^{\circ} \mathrm{C} \mathrm{min}{ }^{-1}$ in a flowing of $150 \mathrm{ml} \mathrm{min}{ }^{-1}$ nitrogen atmosphere. Varied-temperature X-ray powder diffraction (XRPD) of sample was measured on Panakerui Radiometer empyrean by the scan speed $5.0000 \mathrm{deg} \mathrm{min}^{-1}$ from room temperature to $350{ }^{\circ} \mathrm{C}$. Proton nuclear magnetic resonance $\left({ }^{1} \mathrm{H}\right.$ NMR) spectra were recorded on a Bruker $400 \mathrm{MHz}$ spectrometer. The magnetic properties of complex 1 were collected on a Quantum Design MPMS-XL SQUID magnetometer equipped. The variable-temperature direct current (dc) magnetic 
susceptibility data was collected with a 1000 Oe magnet operating from the 2.0 to $300.0 \mathrm{~K}$ range. The alternating-current (ac) susceptibility data was collected in a 3.5 Oe ac field at various ac frequencies. The zero-field-cooling (ZFC) and field-cooling (FC) of complex 1 was collected with a 100 Oe from 2-300 K.

\subsection{Preparation of single crystal of complex 1}

2.2.1 Synthesis of complex 1. The main products are different with the change of molar ratio of reaction substrates (py-2-al and $\mathrm{Fe}\left(\mathrm{NO}_{3}\right)_{3} \cdot 9 \mathrm{H}_{2} \mathrm{O}$ ). The molar ratio of reaction substrates (py-2-al and $\mathrm{Fe}\left(\mathrm{NO}_{3}\right)_{3} \cdot 9 \mathrm{H}_{2} \mathrm{O}$ ) is $1: 1$ at room temperature in methanol, the main product is complex 1 with hemiacetal ligands. ${ }^{27,28}$ While, the main product is 2-(dimethoxymethyl)pyridine when the molar ratio of reaction substrates (py-2-al and $\left.\mathrm{Fe}\left(\mathrm{NO}_{3}\right)_{3} \cdot 9 \mathrm{H}_{2} \mathrm{O}\right)$ is changed to $10: 1$ (Scheme 1). Both the synthesis and the ${ }^{1} \mathrm{H} \mathrm{NMR}\left(\mathrm{CDCl}_{3}\right)$ for 2(dimethoxymethyl)-pyridine can be seen in ESI (Fig. S3 $\dagger$ ).

A solution of $\mathrm{Fe}\left(\mathrm{NO}_{3}\right)_{3} \cdot 9 \mathrm{H}_{2} \mathrm{O}(89.5 \mathrm{mg}, 0.5 \mathrm{mmol})$ in $4 \mathrm{ml}$ $\mathrm{CH}_{3} \mathrm{OH}$ was added by solution of pyridine-2-carboxaldehyde (py-2-al) (53.5 mg, $0.5 \mathrm{mmol})$ in $2 \mathrm{ml} \mathrm{CH}_{3} \mathrm{OH}$. The dark red reaction solution was filtrated after stirring for $15 \mathrm{~min}$, and the filtrate was left undisturbed. Red rectangle single crystals suitable for X-ray diffraction analysis were obtained after 3 days by ether diffusion method under room temperature. ${ }^{1} \mathrm{H}$ NMR $(400$ MHz, MeOD) $\delta 8.74(\mathrm{~d}, J=5.6 \mathrm{~Hz}, 1 \mathrm{H}), 8.62(\mathrm{t}, J=8.1 \mathrm{~Hz}, 1 \mathrm{H})$, $8.16(\mathrm{~d}, J=7.9 \mathrm{~Hz}, 1 \mathrm{H}), 8.03(\mathrm{t}, J=6.2 \mathrm{~Hz}, 1 \mathrm{H}), 5.85(\mathrm{~s}, 1 \mathrm{H}), 3.36$ (s, 3H) (Fig. S1†). Calcd for $\mathrm{C}_{56} \mathrm{H}_{73} \mathrm{Fe}_{10} \mathrm{~N}_{15} \mathrm{O}_{49}$ (\%): C, 24.36; $\mathrm{H}$, 3.17; N, 9.13. Found (\%): C, 24.62; H, 3.08; N, 9.01. Selected IR $\left(\mathrm{KBr}, \mathrm{cm}^{-1}\right): 2936,1650,1608,1383,1353,805,772$, and 675 (Fig. S2†).

2.2.2 X-ray crystallography. Suitable single crystal for complex 1 was selected for X-ray diffraction analysis. The diffraction intensities for complex were collected on Bruker-AXS CCD area detector with graphite-monochromatic Mo-K $\alpha$ radiation $(\lambda=0.071073 \mathrm{~nm})$ using $\omega$ scan mode at $153 \mathrm{~K}$. The structure was solved by the direct $\operatorname{method}^{29}$ and refined by fullmatrix least square techniques on $F^{2}$ with the program of SHELXL-97. ${ }^{30}$ The crystallographic data of complex 1 was shown in Table 1 . All the non-hydrogen atoms were located by direct methods and subsequent difference Fourier syntheses. In complex $\mathbf{1}$, the hydrogen atoms were located by geometrical

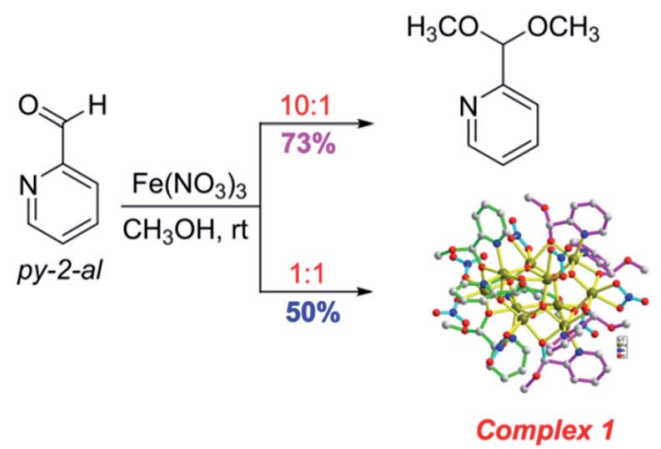

Scheme 1 The formation of complex 1.
Table 1 Crystal data and structure refinement for complex $1^{a, b}$

\begin{tabular}{|c|c|}
\hline Crystal number & 1 \\
\hline Formula & $\mathrm{C}_{56} \mathrm{H}_{73} \mathrm{Fe}_{10} \mathrm{~N}_{15} \mathrm{O}_{49}{ }^{a}$ \\
\hline$M / \mathrm{mol}^{-1}$ & $2298.79^{a}$ \\
\hline$T / \mathrm{K}$ & 153 \\
\hline$\lambda(\mathrm{Mo}-\mathrm{K} \alpha) / \AA$ & 0.71073 \\
\hline Crystal system & Triclinic \\
\hline Space group & $P \overline{1}$ \\
\hline$a / \AA$ & $14.532(3)$ \\
\hline$b / \AA$ & $14.632(3)$ \\
\hline$c / \AA$ & $24.938(5)$ \\
\hline$\alpha /^{\circ}$ & $75.49(3)$ \\
\hline$\beta /^{\circ}$ & $77.55(3)$ \\
\hline$\gamma /{ }^{\circ}$ & $68.01(3)$ \\
\hline$V / \AA^{3}$ & $4716.4(16)$ \\
\hline$Z$ & 2 \\
\hline$\rho$ (calculated) $\mathrm{mg} \mathrm{m}^{-3}$ & 1.637 \\
\hline$\mu, \mathrm{mm}^{-1}$ & 1.592 \\
\hline$F(000)$ & 2352 \\
\hline$\theta$ range $/^{\circ}$ & 2.07 to 31.47 \\
\hline GOF on $F^{2}$ & 1.070 \\
\hline Final $R_{1}^{b}, \mathrm{w} R_{2}^{c}[I>2 \sigma]$ & $0.0844,0.2434$ \\
\hline$R_{1}, \mathrm{w} R_{2}$ (all data) & $0.1137,0.2731$ \\
\hline$\Delta \rho_{\max , \min } / \mathrm{e} \AA^{-3}$ & $1.939,-1.351$ \\
\hline
\end{tabular}

${ }^{a}$ Molecular formula and molecular weight include two $-\mathrm{OH}_{0.5}{ }^{-1.5}$ groups hydrogen atoms not located in the crystal structure. ${ }^{b} R_{1}=$ $\sum|| F_{0}|-| F_{\mathrm{C}}|| / \sum\left|F_{0}\right| \cdot{ }^{c} \mathrm{w} R_{2}=\sum\left[\mathrm{w}\left(F_{0}{ }^{2}-F_{\mathrm{C}}{ }^{2}\right)^{2}\right] / \sum\left[\mathrm{w}\left(F_{0}{ }^{2}\right)^{2}\right]^{1 / 2}$.

calculations, and their positions and thermal parameters were fixed during the structure refinement.

\section{Results and discussion}

The X-ray single-crystal structure determination reveals that complex 1, $\left[\mathrm{Fe}_{10}\left(\mathrm{NO}_{3}\right)_{7}(\mathrm{O})_{6}\left(\mathrm{OH}_{0.5}\right)_{2}((S) \text {-py-hemi })_{4}((R) \text {-py-hemi })_{4}\right]$. $4 \mathrm{H}_{2} \mathrm{O}$, crystallizes in triclinic space group $P \overline{1}$. Complex 1 comprises ten $\mathrm{Fe}(\mathrm{III})$ atoms, seven $\mathrm{NO}_{3}{ }^{-}$, six $\mathrm{O}^{2-}$, two $\mathrm{OH}_{0.5}{ }^{-1.5}$, four $(S)$-py-hemi ligands, four $(R)$-py-hemi ligands and four $\mathrm{H}_{2} \mathrm{O}$ (Fig. 1a). And, the BVS calculations have again confirmed the $\mathrm{Fe}^{\mathrm{III}}$ oxidation states for all $\mathrm{Fe}$ atoms and the degree of protonation of $\mathrm{O}^{2-}$ and $\mathrm{OH}_{0.5}{ }^{-1.5}$ groups (Table 2). ${ }^{31,32}$ The structural characteristics of complex 1 comprise generally an internal part, a ten

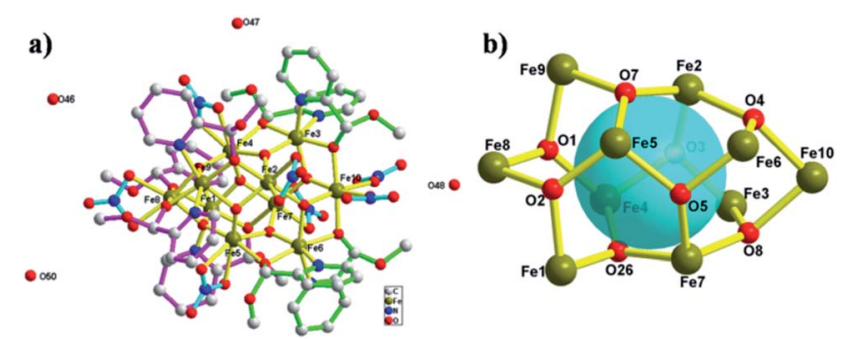

Fig. 1 (a) The coordination environment of complex 1. All $\mathrm{H}$ atoms are omitted for clarity. The (S)-py-hemi ligands, $(R)$-py-hemi ligands, $\mathrm{NO}_{3}{ }^{-}$ groups and $\mathrm{Fe}-\mathrm{O} / \mathrm{N}$ bonds are shown in green color bonds, peach color bonds, light blue color bonds and yellow color bonds, respectively. (b) The football-like cage with eight similar six-membered rings $(\mathrm{O}-\mathrm{Fe}-\mathrm{O}-\mathrm{Fe}-\mathrm{O}-\mathrm{Fe})$ in chair conformation. 
Table 2 Bond valence sums and assignments for Fe atoms and the selected $O$ atoms ${ }^{a}$ in complex 1

\begin{tabular}{lll}
\hline Atom & BVS & Assignment \\
\hline Fe1 & 3.017 & $\mathrm{Fe}^{\mathrm{III}}$ \\
Fe2 & 2.780 & $\mathrm{Fe}^{\mathrm{III}}$ \\
Fe3 & 2.939 & $\mathrm{Fe}^{\mathrm{III}}$ \\
Fe4 & 2.762 & $\mathrm{Fe}$ \\
Fe5 & 2.799 & $\mathrm{Fe}^{\mathrm{III}}$ \\
Fe6 & 3.003 & $\mathrm{Fe}^{\mathrm{III}}$ \\
Fe7 & 2.704 & $\mathrm{Fe}^{\mathrm{III}}$ \\
Fe8 & 2.768 & $\mathrm{Fe}^{\mathrm{III}}$ \\
Fe9 & 2.994 & $\mathrm{Fe}^{\mathrm{III}}$ \\
Fe10 & 2.733 & $\mathrm{Fe}^{\mathrm{III}}$ \\
O1 & 1.756 & $\mathrm{O}^{2-}$ \\
O2 & 1.749 & $\mathrm{O}^{2-}$ \\
O3 & 1.839 & $\mathrm{O}^{2-}$ \\
O4 & 1.399 & $\mathrm{OH}_{0.5}{ }^{-1.5}$ \\
O5 & 1.829 & $\mathrm{O}^{2-}$ \\
O7 & 1.775 & $\mathrm{O}^{2-}$ \\
O8 & 1.397 & $\mathrm{OH}_{0.5}{ }^{-1.5}$ \\
O26 & 1.762 & $\mathrm{O}^{2-}$
\end{tabular}

${ }^{a}$ An O BVS in the $\sim 1.8-2.0, \sim 1.0-1.2$ and $\sim 0.2-0.4$ ranges is indicative of non-, single- and double-protonation, respectively.

$\mathrm{Fe}^{\mathrm{III}}$ atoms cage in a football-like structure (Fig. 1b), and an external part, four $(S)$-py-hemi ligands and four $(R)$-py-hemi ligands in butterfly-like format (Fig. 2). The six $\mu_{3}-\mathrm{O}^{2-}$ atoms $(\mathrm{O} 1, \mathrm{O} 2, \mathrm{O} 3, \mathrm{O} 5, \mathrm{O} 7$ and $\mathrm{O} 26)$ and two $\mu_{3}-\mathrm{OH}_{0.5}{ }^{-1.5}$ groups $(\mathrm{O} 4$, O8) link ten $\mathrm{Fe}^{\mathrm{III}}$ atoms to extent a football-like cage with eight similar six-membered rings (O-Fe-O-Fe-O-Fe) in chair conformation (Fig. 1b). The Fe-O bond lengths in complex 1 can be seen in Table 3.

Four $(S)$-py-hemi ligands and four $(R)$-py-hemi ligands adopt similar coordination mode (Fig. 2). Two adjacent $(S)$-py-hemi ligands with $\mathrm{N} 1$ and $\mathrm{N} 2$ atoms connect to one $\mathrm{Fe}^{\mathrm{III}}$ atom (Fe3) by the N1, N2, O9 and $\mathrm{O} 11$ atoms to extent one butterfly wing structure, and at the same time another two adjacent $(S)$-pyhemi ligands with N7 and N8 atoms adopt similar coordination mode as that of (S)-py-hemi ligands with N1 and N2 atoms

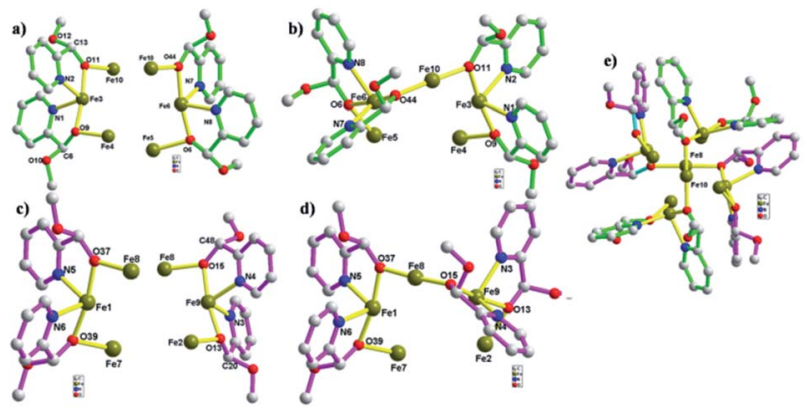

Fig. 2 (a) The butterfly wing structures containing (S)-py-hemi ligands. (b) The distorted butterfly structure containing (S)-py-hemi ligands. (c) The butterfly wing structures containing $(R)$-py-hemi ligands. (d) The distorted butterfly structure containing $(R)$-py-hemi ligands. (e) The packing model of two distorted butterfly structures.
Table $3 \mathrm{Fe}-\mathrm{O}$ bond lengths in complex 1

\begin{tabular}{llll}
\hline Bond & Bond length, $\AA$ & Bond & Bond length, \\
\hline $\mathrm{Fe}(1)-\mathrm{O}(26)$ & $1.964(3)$ & $\mathrm{Fe}(1)-\mathrm{O}(29)$ & $1.966(3)$ \\
$\mathrm{Fe}(1)-\mathrm{O}(12)$ & $1.970(3)$ & $\mathrm{Fe}(1)-\mathrm{O}(9)$ & $1.975(4)$ \\
$\mathrm{Fe}(2)-\mathrm{O}(3)$ & $1.868(3)$ & $\mathrm{Fe}(2)-\mathrm{O}(21)$ & $1.917(4)$ \\
$\mathrm{Fe}(2)-\mathrm{O}(17)$ & $1.991(3)$ & $\mathrm{Fe}(2)-\mathrm{O}(22)$ & $2.102(4)$ \\
$\mathrm{Fe}(2)-\mathrm{O}(30)$ & $2.170(4)$ & $\mathrm{Fe}(2)-\mathrm{O}(31)$ & $2.190(4)$ \\
$\mathrm{Fe}(3)-\mathrm{O}(47)$ & $1.970(3)$ & $\mathrm{Fe}(3)-\mathrm{O}(4)$ & $2.004(3)$ \\
$\mathrm{Fe}(3)-\mathrm{O}(25)$ & $2.047(3)$ & $\mathrm{Fe}(4)-\mathrm{O}(26)$ & $1.893(3)$ \\
$\mathrm{Fe}(4)-\mathrm{O}(23)$ & $1.913(3)$ & $\mathrm{Fe}(4)-\mathrm{O}(3)$ & $1.953(3)$ \\
$\mathrm{Fe}(4)-\mathrm{O}(47)$ & $2.110(3)$ & $\mathrm{Fe}(4)-\mathrm{O}(27)$ & $2.143(4)$ \\
$\mathrm{Fe}(4)-\mathrm{O}(28)$ & $2.251(4)$ & $\mathrm{Fe}(5)-\mathrm{O}(21)$ & $1.891(4)$ \\
$\mathrm{Fe}(5)-\mathrm{O}(29)$ & $1.907(3)$ & $\mathrm{Fe}(5)-\mathrm{O}(19)$ & $1.947(3)$ \\
$\mathrm{Fe}(5)-\mathrm{O}(20)$ & $2.114(4)$ & $\mathrm{Fe}(5)-\mathrm{O}(46)$ & $2.154(5)$ \\
$\mathrm{Fe}(5)-\mathrm{O}(34)$ & $2.247(5)$ & $\mathrm{Fe}(6)-\mathrm{O}(19)$ & $1.925(3)$ \\
$\mathrm{Fe}(6)-\mathrm{O}(20)$ & $1.954(4)$ & $\mathrm{Fe}(6)-\mathrm{O}(18)$ & $2.000(3)$ \\
$\mathrm{Fe}(6)-\mathrm{O}(17)$ & $2.048(4)$ & $\mathrm{Fe}(7)-\mathrm{O}(19)$ & $1.880(3)$ \\
$\mathrm{Fe}(7)-\mathrm{O}(26)$ & $1.940(3)$ & $\mathrm{Fe}(7)-\mathrm{O}(25)$ & $1.987(3)$ \\
$\mathrm{Fe}(7)-\mathrm{O}(12)$ & $2.083(4)$ & $\mathrm{Fe}(7)-\mathrm{O}(15)$ & $2.147(4)$ \\
$\mathrm{Fe}(7)-\mathrm{O}(44)$ & $2.228(4)$ & $\mathrm{Fe}(8)-\mathrm{O}(23)$ & $1.923(4)$ \\
$\mathrm{Fe}(8)-\mathrm{O}(29)$ & $1.926(4)$ & $\mathrm{Fe}(8)-\mathrm{O}(9)$ & $1.997(4)$ \\
$\mathrm{Fe}(8)-\mathrm{O}(24)$ & $2.020(4)$ & $\mathrm{Fe}(8)-\mathrm{O}(43)$ & $2.152(5)$ \\
$\mathrm{Fe}(8)-\mathrm{O}(42)$ & $2.169(5)$ & $\mathrm{Fe}(9)-\mathrm{O}(22)$ & $1.975(4)$ \\
$\mathrm{Fe}(9)-\mathrm{O}(23)$ & $1.962(3)$ & $\mathrm{Fe}(9)-\mathrm{O}(24)$ & $2.000(4)$ \\
$\mathrm{Fe}(9)-\mathrm{O}(21)$ & $1.982(3)$ & $\mathrm{Fe}(10)-\mathrm{O}(6)$ & $2.073(4)$ \\
$\mathrm{Fe}(10)-\mathrm{O}(18)$ & $2.000(4)$ & $\mathrm{Fe}(10)-\mathrm{O}(4)$ & $2.002(4)$ \\
$\mathrm{Fe}(10)-\mathrm{O}(17)$ & $2.014(4)$ & $\mathrm{Fe}(10)-\mathrm{O}(25)$ & $2.020(3)$ \\
$\mathrm{Fe}(10)-\mathrm{O}(13)$ & $2.053(4)$ & & \\
& & &
\end{tabular}

to extent butterfly wing structure (Fig. 2a). And then, the above two butterfly wing structures are connected by a Fe10 atom to extent a distorted butterfly structure (Fig. 2b). Similarly, two $(R)$ py-hemi ligands with N3 and N4 atoms and another two $(R)$-pyhemi ligands with N5 and N6 atoms also connect to two Fe atoms (Fe1 and Fe9) respectively to extent two butterfly wing structures (Fig. 2c). And the two butterfly wing structures with $(R)$-py-hemi ligands are connected by a Fe8 atom to extent another distorted butterfly structure (Fig. 2d). The two deformed butterfly structures are packed together in a direction of near $90^{\circ}$ to extent the external part of complex 1. Each $\mathrm{Fe}^{\mathrm{III}}$ atom is six-coordinated (octahedral geometry). The coordination environment of ten $\mathrm{Fe}^{\mathrm{III}}$ atoms can be divided into four types (I, II, III and IV). Type I: four $\mathrm{Fe}^{\mathrm{III}}$ atoms (Fe1, Fe3, Fe6 and Fe9) adopt similar coordination environment that each $\mathrm{Fe}^{\mathrm{III}}$ atom is six-coordinated by two nitrogen atoms and two oxygen atoms from two homochiral py-hemi ligands and two $\mu_{3}-\mathrm{O}^{2-}$ atoms (Fig. 3a). Type II: four $\mathrm{Fe}^{\mathrm{III}}$ atoms (Fe2, $\mathrm{Fe} 4, \mathrm{Fe} 5$ and $\mathrm{Fe} 7$ ) adopt similar coordination environment that each $\mathrm{Fe}^{\mathrm{III}}$ atom is six-coordinated by one oxygen atom from a py-hemi ligand, two oxygen atoms from one $\mathrm{NO}_{3}{ }^{-}$and three $\mu_{3}-\mathrm{O}^{2-}$ atoms (Fig. 3b). Type III: the Fe8 atom is six-coordinated by two oxygen atoms from two $(R)$-py-hemi ligands, two oxygen atoms from one $\mathrm{NO}_{3}{ }^{-}$ and two $\mu_{3}-\mathrm{O}^{2-}$ atoms (Fig. 3c). Type IV: the Fe10 atom is sixcoordinated by two oxygen atoms from two $(S)$-py-hemi ligands, two oxygen atoms from two $\mathrm{NO}_{3}{ }^{-}$and two $\mu_{3}-\mathrm{O}^{2-}$ atoms (Fig. 3d). Selected bond distances and angles for complex 1 can be seen in Table S1 (ESI $\dagger$ ). 


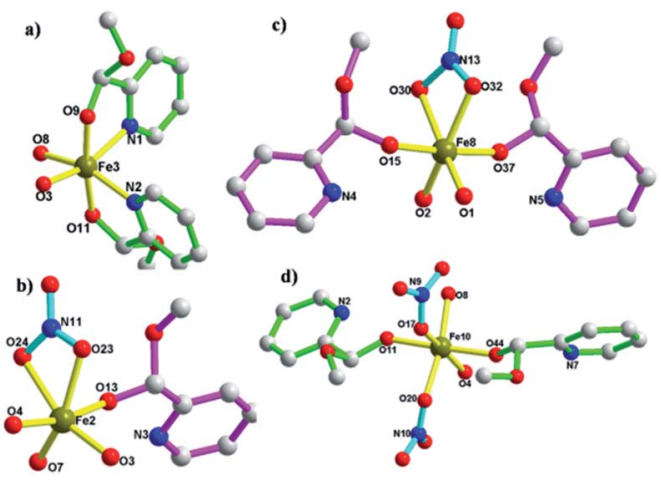

Fig. 3 The coordination environment of ten Fe ${ }^{\text {III }}$ atoms, which can be divided into four types: (a) type I. (b) Type II. (c) Type III. (d) Type IV.

The asymmetric units of complex 1 pack together by $\pi-\pi$ interactions among $(R)$-py-hemi ligands with $\mathrm{N} 3$ atoms with $\pi$ $\pi$ distance $3.762 \AA$ (ref. 33) and van der Waals interactions to extent the 3D structure of complex 1 (Fig. 4). The hemiacetalate ligands with homochirality trends to pack together in the 3D structure of complex $\mathbf{1}$.

\subsection{Physical characterization}

Thermogravimetric analysis (TGA) (Fig. 5a) and variedtemperature PXRD (Fig. S4 in ESI $\dagger$ ) were performed to testify the thermal stability of complex 1. As shown in Fig. 5a, the first weight loss of $3.18 \%$ (calc. $3.13 \%$ ) in the range $25-105{ }^{\circ} \mathrm{C}$ corresponds to the removal of four water solvent molecules. The second weight loss at $105-200{ }^{\circ} \mathrm{C}$ may correspond to the decomposition of part organic ligands (9.87\%). From the variedtemperature PXRD patterns of complex 1, there is no obvious change in the varied-temperature PXRD patterns before $120^{\circ} \mathrm{C}$, the peak of varied-temperature PXRD patterns intensities decrease at $150{ }^{\circ} \mathrm{C}$ due to partial framework decomposition, which may be induced by the decomposition of part organic ligands and the framework already collapses at $350{ }^{\circ} \mathrm{C}$.

Variable temperature dc magnetic susceptibility data in the 2.0-300.0 K range in a 1000 Oe field (Fig. 5b) and alternatingcurrent (ac) susceptibility data (Fig. 5c) were collected on powdered crystalline sample of complex 1. As depicted in Fig. $5 \mathrm{~b}$ and $\mathrm{c}$, at $300 \mathrm{~K}$, the $\chi_{\mathrm{M}} T$ value is $15.8299 \mathrm{~cm}^{3} \mathrm{~mol}^{-1} \mathrm{~K}$ per $\mathrm{Fe}^{3+}$, significantly lower than the value of $43.75 \mathrm{~cm}^{3} \mathrm{~mol}^{-1} \mathrm{~K}$, and the inphase $\left(\chi_{M}^{\prime}\right)$ ac signals for complex $\mathbf{1}$ is temperature-dependent in
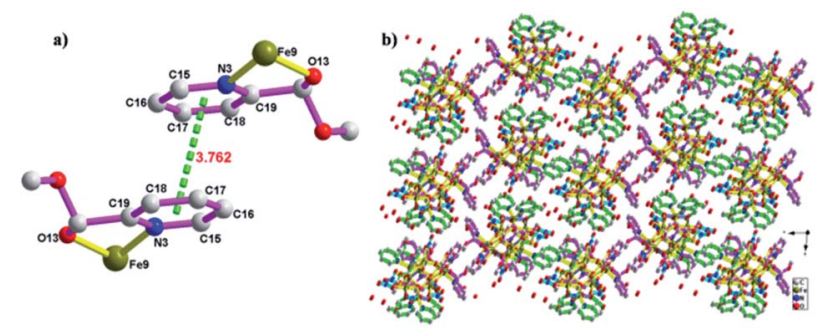

Fig. 4 (a) The $\pi-\pi$ packing model among $(R)$-py-hemi ligands with N3 atoms. (b) The 3D packing picture of complex 1.
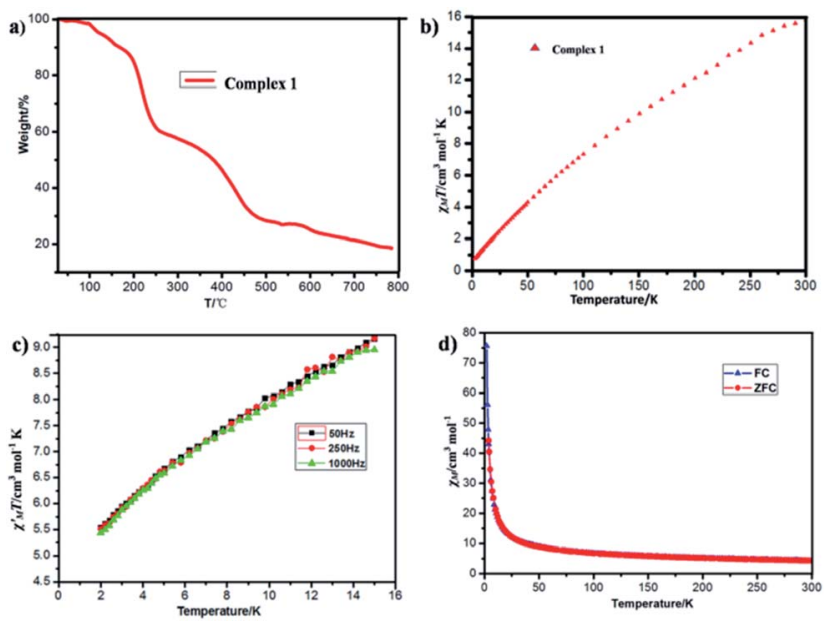

Fig. 5 (a) The thermal gravimetric analysis (TGA) diagram of complex 1. (b) Temperature dependence of $\chi_{M} T$ of complex 1 at $H=1000 \mathrm{Oe}$ from 2-300 K. (c) Temperature dependence of the in-phase components $\left(\chi^{\prime}\right)$ of ac magnetic susceptibility for 1 in a 3.5 Oe ac field at various ac frequencies. (d) The zero-field-cooling (ZFC) and fieldcooling (FC) of complex 1 at $H=100$ Oe from 2-300 K.

the 2-15 $\mathrm{K}$ region and the plot is clearly heading for $\chi_{\mathrm{M}}^{\prime} T \sim 5 \mathrm{~cm}^{3} \mathrm{~K} \mathrm{~mol}^{-1}$ at $0 \mathrm{~K}$, expected for the noninteracting high-spin $\mathrm{Fe}^{3+}$ ion $(S=5 / 2$ and $g=2.00) .^{3}$ The $\chi_{\mathrm{M}} T$ value decreases almost linearly with lowering temperature to $0.7755 \mathrm{~cm}^{3} \mathrm{~mol}^{-1} \mathrm{~K}$ at $2.0 \mathrm{~K}$. The overall behavior is clearly indicative of strong antiferromagnetic interactions between the $\mathrm{Fe}^{3+}$ centers. The zerofield-cooling (ZFC) and field-cooling (FC) curves (Fig. 5d) were measured from $2 \mathrm{~K}$ to $300 \mathrm{~K}$, while the coincident curves indicate that no spontaneous magnetization exist in complex 1.

\section{Conclusions}

In conclusion, a high-nuclearity complex involving a decanuclear iron(III)/oxo cage in football-like structure and unusual $(R$ - $/ S)$-hemiacetalate ligands in butterfly-like format has been successfully synthesized, and it displays strong antiferromagnetism. This demonstrates that the combination of the pyridine-2-carboxaldehyde, methanol and $\mathrm{Fe}^{\mathrm{III}}$ atom can provide a new route to obtain high nuclearity magnetic cluster with unusual racemate ligands, thus giving the opportunity to explore their beautiful structures and interesting magnetism. A further study on the reaction of pyridine-2-carboxaldehyde with other $\mathrm{Fe}^{\mathrm{III}}$ salts and other alcoholic solvents is in progress by our group.

\section{Conflicts of interest}

There is no conflict to declare.

\section{Acknowledgements}

This work was supported by the National Natural Science Foundation of China (Grant no. 21976099, 31570355 and 21102079), Qingdao Postdoctoral Applied Research Project 
(Grant no. 2018111) and National Training Program of Innovation and Entrepreneurship for Undergraduates (201910429007).

\section{Notes and references}

1 X.-M. Luo, Z.-B. Hu, Q.-F. Lin, W. Cheng, J.-P. Cao, C.-H. Cui, H. Mei, Y. Song and Y. Xu, J. Am. Chem. Soc., 2018, 140(36), 11219-11222.

2 L.-P. Cheng, Z. Wang, Q.-Y. Wu, H.-F. Su, T. Peng, G.-G. Luo, Y.-A. Li, D. Sun and L.-S. Zheng, Chem. Commun., 2018, 54, 2361-2364.

3 T. Liu, Y.-J. Zhang, Z.-M. Wang and S. Gao, J. Am. Chem. Soc., 2008, 130, 10500-10501.

4 A. Datta, K. Das, S. B. Mane, S. Mendiratta, M. S. E. Fallah, E. Garribba, A. Bauzá, A. Frontera, C.-H. Hung and C. Sinha, $R S C A d v$., 2016, 6, 54856-54865.

5 S. Ferrer, J. Hernández-Gil, F. J. Valverde-Muñoz, F. Lloretb and A. Castiñeiras, RSC Adv., 2019, 9, 29357-29367.

6 L. G. Christie, S. Asche, J. S. Mathieson and L. V.-N. Cronin, J. Am. Chem. Soc., 2018, 140(30), 9379-9382.

7 R. W. Hogue, S. Singh and S. Brooker, Chem. Soc. Rev., 2018, 47, 7303-7338.

8 C. McDonald, S. Sanz, E. K. Brechin, M. K. Singh, G. Rajaraman, D. Gaynor and L. F. Jones, RSC Adv., 2014, 4, 38182-38191.

9 K. Su, F. Jiang, J. Qian, J. Pan, J. Pang, X. Wan, F. Hu and M. Hong, RSC Adv., 2015, 5, 33579-33585.

10 J. R. Pankhurst, S. Paul, Y. Zhu, C. K. Williams and J. B. Love, Dalton Trans., 2019, 48, 4887-4893.

11 M. K. Singh and G. Rajaraman, Inorg. Chem., 2019, 58(5), 3175-3188.

12 B.-Q. Ji, M. Jagodič, Z. Jagličić, H.-Y. Ma, H.-F. Su, Y.-W. Li, C.-H. Tung and D. Sun, New J. Chem., 2018, 42, 17884-17888.

13 R. H. Sanchez and T. A. Betley, J. Am. Chem. Soc., 2018, 140(48), 16792-16806.

14 D. A. Roberts, B. S. Pilgrim, G. Sirvinskaite, T. K. Ronson and J. R. Nitschke, J. Am. Chem. Soc., 2018, 140(30), 9616-9623.

15 W. Wernsdorfer, N. Aliaga-Alcalde, D. N. Hendrickson and G. Christou, Nature, 2002, 416, 406-409.
16 P. Y. Chen, M. Z. Wu, T. Li, X. J. Shi, L. Tian and Z. Y. Liu, Inorg. Chem., 2018, 57(20), 12466-12470.

17 M. Das, R. Herchel, Z. Trávníček, V. Bertolasi and D. Ray, New J. Chem., 2018, 42, 16717-16728.

18 M. N. Leuenberger and D. Loss, Nature, 2001, 410, 789-793. 19 Y. Zhang, B. Ali, J. Wu, M. Guo, Y. Yu, Z. Liu and J. Tang, Inorg. Chem., 2019, 58(5), 3167-3174.

20 A. A. Kitos, C. Papatriantafyllopoulou, A. J. Tasiopoulos, S. P. Perlepes, A. Escuer and V. Nastopoulos, Dalton Trans., 2017, 46, 3240-3251.

21 M. J. Gajewska, A. Bieńko, R. Herchel, M. Haukka, M. Jerzykiewicz, A. Ożarowski, K. Drabent and C.-H. Hung, Dalton Trans., 2016, 45, 15089-15096.

22 O. Botezat, J. van Leusen, P. Kögerler and S. G. Baca, Inorg. Chem., 2018, 57(13), 7904-7913.

23 T. Taguchi, M. S. Thompson, K. A. Abboud and G. Christou, Dalton Trans., 2010, 39, 9131-9139.

24 A. McSkimming and D. L. M. Suess, Inorg. Chem., 2018, 57, 14904-14912.

25 A. M. Ako, Y. Lan, V. Mereacre, E. Ruiz, D. Aravena, C. E. Anson and A. K. Powell, Dalton Trans., 2013, 42, 9606-9612.

26 S. G. Baca and M. Speldrich, Dalton Trans., 2015, 44, 77777780.

27 K. C. Mondal, O. Sengupta and P. S. Mukherjee, Inorg. Chem. Commun., 2009, 12, 682-685.

28 M. G. B. Drew, S. Nag, P. K. Pal and D. Datta, Inorg. Chim. Acta, 2008, 361, 2562-2567.

29 S. Bruker and B. Saint, SMART and SAINT, Bruker AXS Inc., Madison, 2002.

30 G. M. Sheldrick, A short history of SHELX, Acta Crystallogr., Sect. A: Found. Crystallogr., 2008, 64, 112-122.

31 I. D. Brown and D. Altermatt, Acta Crystallogr., Sect. B: Struct. Sci., 1985, 41, 244-247.

32 E. S. Koumousi, A. Routzomani, T. N. Nguyen, D. P. Giannopoulos, C. P. Raptopoulou, V. Psycharis, G. Christou and T. C. Stamatatos, Inorg. Chem., 2013, 52(3), 1176-1178.

33 Y. Kang, Z. Liao, M. Wu, S. Li, D.-C. Fang, X.-J. Zheng and L.-P. Jin, Dalton Trans., 2018, 47, 13730-13738. 